\title{
Musgos acrocárpicos das Matas de Galeria da Reserva Ecológica do IBGE, RECOR, Distrito Federal, Brasil ${ }^{1}$
}

\author{
Paulo Eduardo Aguiar Saraiva Câmara ${ }^{2,3}$
}

Recebido em 1/01/2007. Aceito em 27/02/2008

\begin{abstract}
RESUMO - (Musgos acrocárpicos das Matas de Galeria da Reserva Ecológica do IBGE, RECOR, Distrito Federal, Brasil). A Reserva Ecológica do IBGE, localizada a $35 \mathrm{~km}$ ao sul do centro da cidade de Brasília é uma das Áreas Núcleo da Reserva da Biosfera do Cerrado, criada pela UNESCO. Neste trabalho são apresentados os musgos acrocárpicos que alí ocorrem e que são representados por 12 famílias e 26 espécies sendo Bryaceae (cinco) a de maior riqueza específica. Foram encontradas quatro novas ocorrências para o Distrito Federal e duas para a região Centro-Oeste. São apresentadas chaves, cometários, distribuição geográfica e diagnoses.
\end{abstract}

Palavras-chave: briófitas, Distrito Federal, IBGE, matas de galeria, musgos

ABSTRACT - (Acrocarpous mosses of the gallery forests at IBGE Ecological Reserve, RECOR, Distrito Federal, Brazil). The IBGE Ecological reserve, located $35 \mathrm{~km}$ from downtown Brasilia, is one of the core areas of the Cerrado Biosphere Reserve created by UNESCO. This article lists 26 species of acrocarpous mosses representing 12 families. Bryaceae (five) was the most species-rich family. Four new occurrences for the Midwestern Region and three for the Distrito Federal are presented. Keys, comments, geographic distribution and diagnoses are provided.

Key words: bryophytes, Distrito Federal, IBGE, gallery forest, mosses

\section{Introdução}

Estima-se que nas regiões tropicais existam mais briófitas do que em qualquer outra região do mundo (Gradstein \& Pócs 1989) e o Distrito Federal é reconhecido como um dos principais centros de diversidade e endemismo de espécies vegetais do Brasil Central (Gentry 1997). Apesar disto, ainda pouco se sabe da brioflora do Centro-Oeste brasileiro, em particular do Distrito Federal. Soma-se a isto o fato de que o cerrado vem sendo devastado de forma acelerada e substituído por monoculturas. Estima-se que o cerrado esteja hoje reduzido a $1 / 3$ da extensão original (Felfili et al. 1994). Surge, então, a necessidade de se realizar inventários da sua brioflora, ampliando o conhecimento e a distribuição das espécies.

No Distrito Federal, até 1984, não existiam publicações ou uma coleção briológica sistematizada e regular. Havia apenas coletas esparsas feitas de forma aleatória e assistemática. As primeiras coletas específicas para a região foram realizadas pelo pesquisador científico Daniel Vital, do Instituto de Botânica de São Paulo, em expedição a Brasília em 1984, sem que os resultados fossem publicados. Após quase uma década deste evento uma listagem prévia para a região do cerrado foi preparada por Filgueiras \& Pereira (1993). Posteriormente, Câmara et al. (2003) publicaram o levantamento da brioflora urbana do Recanto das Emas, Câmara et al. (2005) publicaram um cheklist para o Distritro Federal e Oliveira et al. (2006) publicaram uma listagem parcial das coletas feitas por Daniel Vital para região de Águas Emendadas. Este manuscrito apresenta pela primeira vez chaves e diagnoses para a Reserva, preenchendo assim uma importante lacuna na briologia do Centro-Oeste brasileiro.

\section{Material e métodos}

Devido ao grande número de táxons encontrados, optou-se por publicar separadamente os resultados referentes aos musgos pleurocárpicos e acrocárpicos. As hepáticas e os antóceros foram publicados por Câmara \& Costa (2006). Utilizou-se aqui o conceito de acrocarpia de La-Farge-England (1996).

Área estudada - O Distrito Federal possui uma área de $5.822,1 \mathrm{~km}^{2}$, sendo coberto pela vegetação de cerrado sensu lato, em altitudes que variam entre 750 e $1.350 \mathrm{~m}$ (SEMATEC 1992). De modo geral sua flora é apenas parcialmente conhecida (Filgueiras \& Pereira 1993), em particular, a brioflora. A região tem clima com duas

\footnotetext{
1 Parte da Dissertação de Mestrado do Autor, Departamento de Botânica da Universidade de Brasília, DF, Brasil

2 Missouri Botanical Garden, PoBox 299, Saint Louis, MO, 63110, USA (paulo.camara@mobot.org)

3 Universidade de Brasília, Departamento de Botânica, C. Postal 04457, 70910-970 Brasília, DF, Brasil
} 
estações bem definidas, uma fria e seca (entre maio e setembro) e outra quente e úmida (entre outubro e abril). Segundo a classificação de Köppen o clima é Aw, ou seja, tropical de savana (SEMATEC 1992).

Situada a $35 \mathrm{~km}$ ao sul do centro de Brasília, no km 0 da BR 251, a Reserva Ecológica do Instituto Brasileiro de Geografia e Estatística (IBGE), ou Reserva Ecológica do Roncador (RECOR), localiza-se a $15^{\circ} 56^{\prime} 41^{\prime \prime} \mathrm{S}$ e 47 $53^{\prime} 07^{\prime \prime}$ W. Possui uma área de 1.350 ha, com todos os tipos fisionômicos do cerrado, fazendo parte da Área de Proteção Ambiental (APA) Gama-Cabeça de Veado, que inclui ainda a Reserva Ecológica do Jardim Botânico de Brasília e a Fazenda Água Limpa (da Universidade de Brasília), o que perfaz 10.000 ha de área protegida contínua. Além disto, a RECOR, criada em 1993 pela UNESCO, é uma das Áreas Núcleo da Reserva da Biosfera do Cerrado (Pereira \& Mamede 1993).

A RECOR possui as nascentes de cinco cursos d'água, denominados Escondido, Monjolo, Pitoco, Roncador e Taquara formando a Bacia do Córrego Taquara, afluente pela margem direita do Ribeirão do Gama, um dos principais tributários do reservatório do Paranoá.

As matas de galeria totalizam na RECOR ca. 104 ha e destacam-se por sua riqueza, diversidade genética e pelo importante papel na proteção dos recursos hídricos, fauna silvestre e aquática (Rezende 1998). Os estudos fanerogâmicos destas matas têm revelado a mais diversa flora arbórea do Brasil Central (Silva
Júnior et al. 1998). As matas de galeria atuam também como barreira física, regulando os processos de troca entre os sistemas terrestres e aquáticos. Têm ainda papel importante na redução da contaminação dos cursos d'água por sedimentos, resíduos de adubos e pelo escoamento superficial de água no terreno (Rezende 1998). Estudos sobre a flora em matas de galeria do cerrado estão focados principalmente na vegetação fanerogâmica, com poucos estudos realizados sobre a sua brioflora (Genevro et al. 2006).

Amostragem - Foram realizadas coletas aleatórias, entre outubro/2000 e abril/2001. As técnicas de coleta e preservação seguem Yano (1984). Todo o material coletado está depositado nos herbários UB e IBGE. Quando necessário para identificação foram preparadas lâminas permanentes com solução de Hoyer (Anderson 1954). O material foi identificado com auxílio de bibliografia especializada, comparação em herbários (UB, SP, RB, IBGE e HEPH) e, quando necessário, enviado a especialistas.

A distribuição geográfica foi baseada na literatura e o sistema de classificação utilizado foi o de Buck \& Goffinet (2000), exceto para o gênero Octoblepharum, aqui considerado como Leucobryaceae (Vitt 1984). Acredita-se que assim a identificação do material será mais fácil, em especial quando estéril (frequentemente assim encontrado na RECOR).

As chaves elaboradas são artificias e se destinam à identificação exclusiva de material oriundo da RECOR.

\section{Resultados e discussão}

\section{Chave para famílias}

1. Plantas esbranquiçadas ou verde claro; filídios com leucocistos ….................................................................2

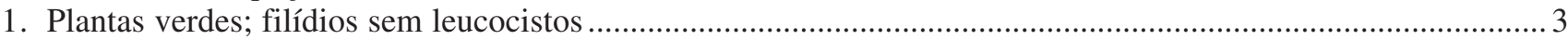

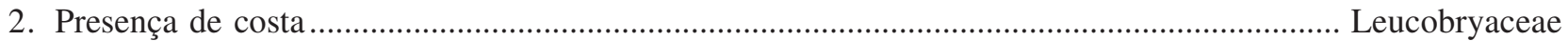

2. Ausência de costa ................................................................................................................ Sphagnaceae

3. Filídios dísticos, com lâmina vaginante ................................................................................ Fissidentaceae

3. Filídios dispostos em espiral, com lâmina única ...................................................................................... 4

4. Lamelas ao longo da superfície dorsal da costa ........................................................... Polytrichaceae

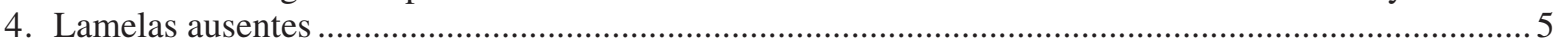

5. Filídios com células alares ou hialinas ............................................................................... 6

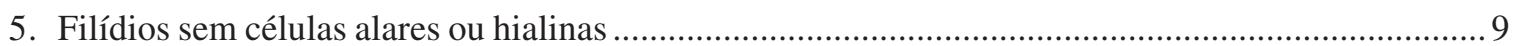

6. Costa conspícua ocupando cerca de $1 / 2$ da base ................................................ Dicranaceae

6. Costa inconspícua ocupando menos de $1 / 2$ da base .............................................................. 7

7. Células hialinas maiores que os clorocistos .............................................. Calymperaceae

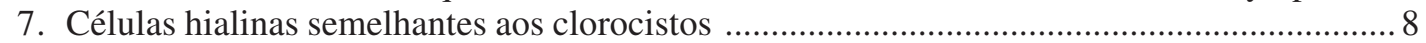

8. Costa subpercurrente; atingindo no máximo 3/4 do comprimento do filídio;

Rhachitheciaceae

8. Costa percurrente; atingindo sempre o ápice do filídio ..................................... Pottiaceae

9. Gametófitos maiores que $10 \mathrm{~mm}$, ramificados; filídios espiralados quando secos, células com paredes espessas ............................................. Orthotrichaceae

9. Gametófitos menores que $10 \mathrm{~mm}$ compr., não ramificados; filídios não espiralados quando secos, células com paredes delgadas 
10. Filídios com células apicais papilosas .......................................... Bartramiaceae

10. Filídios com células apicais lisas 11

11. Filídios com margem diferenciada

11. Filídios sem margem

Bryaceae Funariaceae

\section{BARTRAMIACEAE}

1. Philonotis uncinata (Schwägr.) Brid., Bryol. Univ. 2: 22.1827.

Gametófitos ca. 9 mm compr., não ramificados; filídios dispostos densamente, células apicais unipapilosas; costa percurrente; margem serreada e ápice agudo; esporófito não observado.

Descrição e ilustração: Sharp et al. (1994)

Material examinado: BRASIL. Distrito Federal: Reserva Ecológica do IBGE, solo da mata de galeria do rio Monjolo, 21/II/2001, Câmara 518, 520 (UB, IBGE).

Distribuição geográfica: AC, AM, BA, DF, ES, GO, MG, MS, MT, PA, PB, PE, PI, PR, RO, RJ, RS, SC, SP, TO.

Comentários: planta terrestre de ambientes úmidos.

\section{BRYACEAE}

Chave para espécies:

1. Planta de coloração acinzentada ou prateada 3. Bryum argenteum

1. Planta de coloração verde

2. Filídios com margem serrilhada 6. B. densifolium

2. Filídios com margem inteira

3. Filidios obovado-lanceolados 4. Plagiobryum capillare

3. Filidios lanceolados

4. Costa excurrente 5. B. coronatum

4. Costa percurrente

2. B. apiculatum

2. Bryum apiculatum Schwägr., Spec. Musc. Suppl. 2: 102. pl. 72. 1816.

Gametófitos pequenos, ca. $4 \mathrm{~mm}$ alt., crispados quando secos; filídios ca. $1 \mathrm{~mm}$ compr., lanceolados; costa única, percurrente, lisa; ápice longo-acuminado; margem diferenciada, inteira, formada por células alongadas, estreitas, lisa; esporófito não observado.

Descrição e ilustração: Sharp et al. (1994).

Material examinado: BRASIL. Distrito Federal: Reserva Ecológica do IBGE, sobre pedra na nascente do córrego Roncador, 1/IX/2000, Câmara 449 (UB, IBGE); ibidem, crescendo sobre o solo na mata do Pitoco, Câmara 450 (UB, IBGE); ibidem, sobre solo, córrego Taquara, 13/III/1991, Silva 158 (IBGE).
Distribuição geográfica: AC, AM, BA, PB, DF, GO, MA, MG, PA, RJ, RS, SC, SP.

Comentários: terrestre ou saxícola, com preferência por locais abertos.

3. Bryum argenteum Hedw., Spec. Musc. Frond.: 181. 1801.

Gametófitos pequenos, ca. $4 \mathrm{~mm}$ alt., crispados quando secos, de coloração acinzentada ou prateada; filídios ca. $1 \mathrm{~mm}$ compr., obovados; costa única, percurrente, lisa; células hialinas presentes na metade superior do filídio; ápice abrupto-acuminado; margem diferenciada, formada por células alongadas, estreitas, lisas; esporófito não observado.

Descrição e ilustração: Sharp et al. (1994).

Material examinado: BRASIL. Distrito Federal: Reserva Ecológica do IBGE, tronco de árvore no córrego Roncador, 6/XI/1979, Garcia s.n. (UB).

Distribuição geográfica: AM, AL, BA, CE, DF, PB, PE, PR, ES, GO, MG, MT, RJ, RO, RS, SC, SP.

Comentários: cosmopolita e eurisubstrática, é encontrada em áreas alteradas tais como ao redor da sede, alojamentos, guarita, postes, beira do asfalto. Espécie bem adaptada a ambientes perturbados. Facilmente reconhecida pela coloração acinzentada, que lhe conferiu o epíteto de argenteum (prateado). Embora sua coloracão possa variar bastante, no IBGE mostrou-se sempre uniforme e característicamente acinzentada.

4. Plagiobryum capillare (Hedw.) N. Pedersen, Bryol. 108: 126. 2005

Gametófitos não ramificados, pequenos, ca. $8 \mathrm{~mm}$ alt., crispados quando secos; filídios ca. 1,5 mm compr., obovados-lanceolados; costa única, longo-excurrente, lisa; ápice longo-acuminado; margem lisa formada por células diferenciadas, alongadas, estreitas; esporófito não observado.

Descrição e ilustração: Sharp et al. (1994).

Material examinado: BRASIL. Distrito Federal: Reserva Ecológica do IBGE, sobre solo no córrego Roncador, 26/I/2001, Câmara 578 (UB, IBGE); ibidem, sobre cupinzeiro, córrego Monjolo, 14/VI/1994, Silva 2338 (IBGE).

Distribuição geográfica: AM, BA, CE, DF ES, GO, MS, MG, MT, PA, PE, PI, PR, RJ, RO, RS, SC, SP.

Comentários: caracteriza-se por filídios com costa longo-excurrente. Trata-se de uma espécie com grande 
amplitude ecológica (Lisboa 1993), encontrada freqüentemente nas áreas alteradas como alojamentos, prédios e margem das pistas asfaltadas.

5. Bryum coronatum Schwägr., Sup. Spec. Musc. 1(2): 103. 1816.

Gametófitos pequenos, ca. $3 \mathrm{~mm}$ alt., crispados quando secos; filídios ca. 1,5 mm compr., lanceolados; costa única, excurrente, lisa; ápice agudo-acuminado; margem lisa diferenciada, formada por células alongadas, estreitas; seta ca. $3 \mathrm{~mm}$ compr.; cápsula pêndula, cilíndrica, rugosa e dilatada na base.

Descrição e ilustração: Lisboa (1993).

Material examinado: BRASIL. Distrito Federal: Reserva Ecológica do IBGE, sobre o solo na mata do córrego Taquara, 28/V/1990, Arlé s.n. (IBGE).

Distribuição geográfica: AC, AM, BA, DF, FN, GO, MA, MG, MT, PA, PB, PE, PR, RJ, RO, RR, RS, SC, SP.

Comentários: trata-se de uma espécie polimórfica, variando principalmente na forma dos filídios que vão de lanceolados a apiculados ou obovados. Quando fértil, caracteriza-se pelo esporófito com cápsula pêndula de base dilatada e rugosa, mais larga e que lhe rendeu o epíteto coronatum (latim, coronatus = coroado), pois esta estrutura lembraria uma coroa acima do esporófito. Quando estéril pode confundir-se com outras espécies de Bryum, (como Bryum apiculatum). Embora a espécie seja muito comum nas áreas com acentuada ação antrópica, como os prédios e alojamentos da RECOR, nas matas de galeria foi observada apenas uma ocorrência.

6. Rosulabryum densifolium (Brid.) Ochyra, Biodiversity of Poland 3: 162. 2003.

Gametófitos robustos, ca. $3 \mathrm{~cm}$ alt., crispados quando secos; filídios ca. $3,5 \mathrm{~mm}$ compr., obovados-lanceolados; costa única, excurrente, lisa; ápice longoacuminado; margem diferenciada, formada por células, alongadas, estreitas, serrilhada; esporófito não observado.

Descrição e ilustração: Sharp et al. (1994).

Material examinado: BRASIL. Distrito Federal: Reserva Ecológica do IBGE, sobre tronco podre no solo da mata do Monjolo, 6/XI/2000, Câmara 474 (UB, IBGE); ibidem, sobre tronco no chão, córrego Monjolo, 26/I/2001, Câmara 483 (UB, IBGE); ibidem, base de árvore, nascente do córrego Taquara, 26/I/2001, Câmara 492, 500 (UB, IBGE); ibidem, crescendo no solo, córrego Monjolo, 6/II/2001, Câmara 512 (UB, IBGE).

Distribuição geográfica: AC, BA, DF, ES, MG, PE, PR, RJ, RS, SC, SP, TO.

Comentários: caracteriza-se pelo gametófito ereto, robusto ca. $3 \mathrm{~cm}$ alt. e seus filídios com margem serrilhada, especialmente no ápice e filídios grandes (ca. 3,5 mm compr.).

\section{CALYMPERACEAE}

Chave para espécies de Syrrhopodon

1. Filídios com propágulos 9. S. parasiticus

1. Filídios sem propágulos

2. Filídios até $1,5 \mathrm{~mm}$ compr., ligulados 8. S. ligulatus

2. Filídios maiores que $2,0 \mathrm{~mm}$ compr., oblongos

3. Costa espinhosa 10. S. prolifer

3. Costa lisa.... 7. S. gaudichauii

7. Syrrhopodon gaudichaudii Mont., Ann. Sci. Nat., ser. 2, 2: 376. 1834.

Gametófitos, pequenos a medianos, ca. 5-10 mm alt., crispados quando secos; filídios ca. $2 \mathrm{~mm}$, ápice levemente serrilhado; costa única, percurrente, lisa; células hialinas grandes, quadrado-retangulares, bem diferenciadas das clorofiladas, ocupando até quase a metade do filídio; esporófito não observado.

Descrição e ilustração: Reese (1993).

Material analisado: BRASIL. Distrito Federal: Reserva Ecológica do IBGE, sobre tronco de árvore no córrego Taquara, 1/XI/2000, Câmara 462 (UB, IBGE); ibidem, tronco de árvore, córrego Escondido, 21/II/2001, Câmara 528 (UB, IBGE); ibidem, tronco caído, córrego Roncador, 30/IX/1981, Moreira 14 (UB), ibidem, sobre casca, córrego Monjolo, 13/03/1991, Silva 833 (IBGE).

Distribuição geográfica: AM, BA, DF, ES, GO, MA, MG, MT, PA, PE, PR, RJ, RS, SC, SP.

Comentários: espécie corticícola, facilmente confundida com Syrrhopodon prolifer da qual se diferencia pela costa lisa.

\section{Syrrhopodon ligulatus Mont., Syll. Gen. Sp. Crypt.:} 47, 1856.

Gametófitos não ramificados, pequenos, ca. 3-5 mm compr., crispados quando secos; filídios ca. $1,5 \mathrm{~mm}$, ligulados, ápice retuso a obovado; costa única, percurrente, lisa; células hialinas ca. $5 \times$ maiores que as clorofiladas, retangulares a arredondadas, ocupando apenas a base; esporófito não observado.

Descrição e ilustração: Reese (1993).

Material examinado: BRASIL. Distrito Federal: Reserva Ecológica do IBGE, sobre tronco de árvore, córrego Monjolo, 1/X/1996, Costa 3316 (RB); ibidem, sobre tronco árvore, córrego Taquara, 6/XI/2000, Câmara 466-A, 466-B (UB, IBGE); ibidem, base de 
árvore, córrego Taquara, 26/I/2001, Câmara 492, 493 (UB, IBGE); ibidem, sobre tronco de árvore, córrego escondido, 6/II/2001, Câmara 513 (UB, IBGE); ibidem, sobre tronco de árvore, córrego Pitoco, 12/IV/2001, Câmara 558 (UB, IBGE); ibidem, sobre tronco de árvore, córrego Pitoco, 15/IX/2001, Câmara 572, 573 (UB, IBGE); ibidem, sobre tronco de árvore, córrego Escondido, 15/IX/2001, Câmara 590, 591 (UB, IBGE).

Distribuição geográfica: AM, AP, BA, DF, GO, MG, MS, MT, PA, PE, RJ, RO, RR, SP.

Comentários: facilmente reconhecida por seus filídios de forma ligulada e ápice retuso. Na RECOR, ocorre apenas como corticícola.

9. Syrrhopodon parasiticus (Brid.) Besch., Ann. Sci. Nat. Bot. ser. 4, 1: 298, 1895.

Bryum parasiticum Brid., Musc. Rec. 2(3): 54. 1803

Gametófitos pequenos a medianos, ca. 4-15 mm compr., crispados quando secos; filídios ca. $3 \mathrm{~mm}$, lanceolados; costa única, percurrente, lisa; propágulos filamentosos ao longo da costa; células hialinas ca. $2 \times$ maiores e bem diferenciadas que as clorofiladas, retangulares, terminando em ângulos agudos acima, ocupando apenas a base, ápice agudo; esporófito não observado.

Descrição e ilustração: Reese (1993).

Material examinado: BRASIL. Distrito Federal: Reserva Ecológica do IBGE, sobre tronco de árvore, córrego Taquara, 1/XI/2000, Câmara 462 (UB, IBGE); ibidem, sobre tronco de árvore, córrego Escondido, 15/IX/2001, Câmara 578 (UB, IBGE); ibidem, 15/IX/2001, sobre tronco de árvore, córrego Pitoco, Câmara 595 (UB, IBGE).

Distribuição geográfica: AC, AM, BA, DF, ES, MG, MS, MT, PA, PE, PR, RJ, RO, RR, SC, SP.

Comentários: reconhecida por apresentar propágulos filamentosos ao longo da costa, além de filídios lanceolados com células hialinas pequenas. Corticícola.

10. Syrrhopodon prolifer Schwägr., Spec. Musc. Suppl. 2(2): 99. 1827.

Gametófitos, pequenos a medianos, ca. 5-10 mm alt., crispados quando secos, ápice serrilhado; filídios ca. $2 \mathrm{~mm}$; costa única, percurrente, espinhosa; células hialinas ca. $5 \times$ maiores e bem diferenciadas que as clorofiladas, quadrado-retangulares, ocupando até quase a metade do filídio; esporófito não observado.

Descrição e ilustração: Reese (1993).

Material examinado: BRASIL. Distrito Federal: Reserva Ecológica do IBGE, sobre tronco de árvore, córrego Escondido, 21/II/2001, Câmara 535 (UB, IBGE); ibidem, sobre tronco de árvore, córrego Escondido, 15/IX/2001, Câmara 580, 592 (UB, IBGE); ibidem, no solo, córrego Roncador, 3/IX/1981, Pesantes
06 (UB); ibidem, sobre tronco caído, córrego Roncador, 3/IX/1981, Moreira s.n. (UB); ibidem, sobre solo, córrego Roncador, 3/IX/1981, Magalhães 11 (UB).

Distribuição geográfica: AM, BA, GO, DF, PA, PE, PR, MG, MT, RJ, RO, RS, SE, SC, SP.

Comentários: confundida com Syrrhopodon gaudichaudii do qual se diferencia pela costa espinhosa e filídios propagulíferos.

\section{DICRANACEAE}

11. Campylopus controversus (Hampe) A. Jaeger, Ber. Thätigk. St. Gallischen. Naturwiss. Ges. 1877-78: 385. 1880.

Gametófitos grandes, ca. 5-7 cm compr., crispados quando secos; filí́dios ca. $7 \mathrm{~mm}$, lanceolados, ápice serrilhado; costa única, excurrente, até $1 / 3$ da base do filídio; células alares grandes; células basais laminares retangulares; esporófito não observado.

Descrição e ilustração: Frahm (1991).

Material examinado: BRASIL. Distrito Federal: Reserva Ecológica do IBGE, sobre o solo, córrego Escondido, 15/IX/2001, Câmara 577 (UB, IBGE).

Distribuição geográfica: MG, RJ, RS, SP. Primeira ocorrência para o Centro-Oeste.

Comentários: na RECOR foi encontrada sempre associada com Sphagnum perichaetiale, no córrego Escondido, sobre solo, atingindo cerca de $7 \mathrm{~cm}$ altura. É reconhecida pelo seu grande porte. Difere no hábito de Campylopus occultus que é corticícola.

12. Campylopus occultus Mitt., J. Linn. Soc. Bot. 12: 86. 1869.

Gametófitos, corticícolas, ca. $1 \mathrm{~cm}$ alt., crispados quando secos; filídios ca. $2,5 \mathrm{~mm}$, lanceolados, ápice liso; costa única, excurrente, 1/2 da largura da base do filídio; células alares grandes; células basais laminares retangulares; esporófito não observado.

Descrição e ilustração: Frahm (1991).

Material examinado: BRASIL. Distrito Federal: Reserva Ecológica do IBGE, sobre tronco caído no córrego Roncador, III/1981, Pesantes 07 (UB).

Distribuição geográfica: BA, DF, ES, GO, MA, MS, PR, RJ, RS, SC, SP.

Comentários: diferencia-se de Campylopus controversus pelo menor porte, costa mais larga e base do filídio mais abaulada além de hábito corticícola. Campylopus controversus foi encontrada sempre terrestre e associada a Sphagnum.

\section{FISSIDENTACEAE}

13. Fissidens submarginatus Bruch in Kraus, Flora 29: 133. 1846. 
Gametófitos não ramificados, pequenos, ca. $1 \mathrm{~mm}$ compr.; filídios dísticos, aplanados, lanceolados, células unipapilosas, ápice agudo a apiculado e ca. 0,5 mm; lâmina vaginante conduplicada presente; presença de limbídio; costa única, percurrente, lisa; esporófito não observado.

Material examinado: BRASIL. Distrito Federal: Reserva Ecológica do IBGE, base de uma árvore, córrego Taquara, 26/I/2001, Câmara 492 (UB, IBGE).

Distribuição geográfica: AC, AM, BA, DF, ES, FN, GO, MA, MG, MS, MT, PA, PB, PE, PI, RJ, RN, RO, RS, SC, SP.

Comentários: é muito similar a Fissidens intromarginatus, diferenciando-se desta pelas células dos filídios serem pluripapilosas.

\section{FUNARIACEAE}

14. Funaria hygrometrica Hedw., Spec. Musc. Frond.: 172. 1801.

Gametófitos, pequenos, ca. $6 \mathrm{~mm}$ alt., crispados quando secos; filídios simétricos, oblongo-ovados, ápice apiculado e ca. 2,5 mm compr.; costa única, delgada, percurrente a excurrente, lisa; seta longa, 2-3 cm compr.; cápsula assimétrica, recurvada; peristômio duplo com dentes oblíquos quando secos.

Descrição e ilustração: Sharp et al. (1994).

Material examinado: BRASIL. Distrito Federal: Reserva Ecológica do IBGE, sobre solo, córrego Taquara, 28/V/1990, Arlè s.n. (IBGE); ibidem, 13/III/1991, sobre solo, córrego Roncador, Silva 399 (IBGE).

Distribuição geográfica: AM, BA, GO, DF, MG, MT, PE, RJ, PR, SC, SP.

Comentários: as características mais marcantes desta espécie são a cápsula assimétrica, recurvada e o peristômio duplo, com dentes oblíquos. Outra característica é o tamanho do esporófito (com até $3 \mathrm{~cm}$, enquanto o gametófito tem apenas, em média, $6 \mathrm{~mm}$ compr.). Ocorre sempre sobre solos, inclusive de áreas perturbadas, sendo citada como pioneira em ambientes queimados (Crum 1976). As amostras coletadas na RECOR estavam todas férteis.

\section{LEUCOBRYACEAE}

\section{Chave para as espécies:}

1. Plantas com propágulos .2

2. Propágulos no ápice dos filídios 6. Ochrobryum gardneri

2. Propágulos num pequeno ramo no ápice do gametófito ... 17. Ochrobryum subulatum 1. Plantas sem propágulos
3. Filídios esquarrosos, oblongos 18. Ochrobryum albidum

3. Filídios eretos, lanceolados 15. Leucobryum martianum

15. Leucobryum martianum (Hornsch.) Hampe ex Müll. Hal., Linnaea 17: 317. 1843.

Gametófitos branco-esverdeados, ca. $2 \mathrm{~mm}$ alt., homômalos quando secos; filídios eretos, fortemente falcados, lanceolados, ca. 0,3 mm compr.; costa única, alcançando quase a largura do filídio, percurrente, lisa; esporófito não observado.

Descrição e ilustração: Sharp et al. (1994).

Material examinado: BRASIL. Distrito Federal: Reserva Ecológica do IBGE, sobre tronco de árvore, córrego Monjolo, 1/X/1996, Costa 3320 (RB).

Distribuição geográfica: AC, AM, AP, BA, CE, DF, ES, MG, MT, PA, PE, PR, RJ, RO, RR, SC, SE, SP.

Comentários: caracteriza-se por seus filídios homômalos e fortemente falcados, no que se distingue do gênero Ochrobryum. Não foram observadas formas assexuais de reprodução (muito freqüentes nos representantes de Ochrobryum). Na RECOR, o espécime apresentou-se corticícola, mas pode ter hábito saxícola ou terrestre.

16. Ochrobryum gardneri (Müll. Hal.) Mitt., J. Linn. Soc. Bot. 12: 108. 1869.

Gametófitos branco-esverdeados, não ramificados, ca. $3 \mathrm{~mm}$ compr., crispados quando secos; filídios eretos, ápice gradualmente acuminado, longo-lanceolados, ca. $2 \mathrm{~mm}$ compr.; propágulos originando-se no ápice dos filídios; costa única, percurrente, lisa; esporófito não observado.

Descrição e ilustração: Allen (1992).

Material examinado: BRASIL. Distrito Federal: Reserva Ecológica do IBGE, sobre tronco no solo da mata, córrego Taquara, 1/XI/2000, Câmara 457, Câmara 469 (UB, IBGE); ibidem, sobre tronco no solo da mata, córrego Monjolo, 1/XI/2000, Câmara 471 (UB, IBGE); ibidem, sobre tronco no chão, córrego Monjolo, 26/I/2001, Câmara 480 (UB, IBGE); ibidem, Tronco de árvore, córrego Taquara, 26/I/2001, Câmara 492 (UB, IBGE); ibidem, sobre tronco de árvore, córrego Escondido, 21/II/2001, Câmara 528 (UB, IBGE); ibidem, tronco árvore, córrego Escondido, 15/IX/2001, Câmara 579 (UB, IBGE).

Distribuição geográfica: BA, DF, GO, MG, MS, MT, PA, PE, RO, SP.

Comentários: destaca-se pelos propágulos muito freqüentes nos ápices dos filídios.

17. Ochrobryum subulatum Hampe, J. Bot. (Morot) 11: 150. 7. 1897.

Gametófitos branco-esverdeados, ca. 2 mm compr., crispados quando secos; filídios eretos, ápice gradual- 
mente acuminado, longo-lanceolados, ca. $2,5 \mathrm{~mm}$ compr.; presença de propágulos originados no ápice do gametófito, agrupados em pequenos ramos; costa única, percurrente, lisa; esporófito não observado.

Descrição e ilustração: Allen (1992).

Material examinado: BRASIL. Distrito Federal: Reserva Ecológica do IBGE, sobre tronco no solo, córrego Pitoco, 15/IX/2001, Câmara 600 (UB, IBGE).

Distribuição geográfica: AC, AM, AL, GO, MT, PA, PE, RO, SP. Primeira citação para o DF.

Comentários: espécie corticícola. Destaca-se pelos ramos propagulíferos muito freqüentes.

18. Octoblepharum albidum Hedw., Spec. Musc.

Frond.: 50. 1801.

Gametófitos branco-amarelados, não ramificados, pequenos, ca. $2,5 \mathrm{~mm}$ alt., esquarrosos e recurvados quando secos; filídios eretos oblongos, ápice ligulado e apiculado, ca. $3 \mathrm{~mm}$ compr.; costa única, percurrente, lisa; seta mediana, ca. $5 \mathrm{~mm}$ compr.; cápsula ovóide; peristômio simples; caliptra cuculada.

Descrição e ilustração: Sharp et al. (1994).

Material examinado: BRASIL. Distrito Federal: Reserva Ecológica do IBGE, sobre tronco de árvore, córrego Taquara, 1/XI/2000, Câmara 464, 466-A, 466-B (UB, IBGE); ibidem, sobre tronco de árvore, córrego Monjolo, 26/I/2001, Câmara 481 (UB, IBGE); ibidem, sobre tronco de árvore, córrego Taquara, 26/I/2001, Câmara 492, 493, 496, 500 (UB, IBGE); ibidem, sobre tronco de árvore, córrego Pitoco, 12/IV/2000, Câmara 558 (UB, IBGE); ibidem, sobre tronco de árvore, córrego Pitoco, 1/IV/2001, Câmara 571, 573 (UB, IBGE); ibidem, sobre tronco de árvore, córrego Escondido, 15/IX/2001, Câmara 590 (UB, IBGE); ibidem, sobre tronco de árvore córrego Pitoco, 15/IX/2001 Câmara 597, 599 (UB, IBGE); ibidem, sobre rocha, córrego Monjolo, 14/VI/1994, Silva 2339 (IBGE); ibidem, sobre tronco caído, córrego Roncador, 14/VI/1994, Souza s.n. (UB).

Distribuição geográfica: AC, AM, AP, BA, CE, DF, ES, FN, GO, MA, MG, MS, MT, PA, PB, PE, PI, PR, RJ, RO, RR, SC, SE, SP.

Comentários: é bem diferenciada por sua coloração verde clara ou mesmo branca e seus filídios esquarrosos com ápice apiculado. Apresentou-se freqüentemente fértil. Na RECOR foi encontrada apenas corticícola, podendo ser terrestre ou saxícola.

\section{ORTHOTRICHACEAE}

1. Células hialinas papilosa

19. Macromitrium guatemalense

1. Células hialinas lisas

2. Filídios rugosos ...... 20. Schlotheimia rugifolia

2. Filídios lisos 21. S. jamesonii
19. Macromitrium guatemalense Müll. Hal., Syn. Musc. Frond. 2: 644. 1851.

Gametófitos medianos, ca. $10 \mathrm{~mm}$ alt., filídios torcido-espiralados quando secos, ca. $3 \mathrm{~mm}$ compr., eretos, filídios oblongo-lanceolados, ápice mucronado, margem lisa, células retangulares a lineares, paredes espessa; costa única, percurrente, lisa; células hialinas papilosas; esporófito não observado.

Descrição e ilustração: Sharp et al. (1994).

Material examinado: BRASIL. Distrito Federal: Reserva Ecológica do IBGE, sobre tronco de árvore, córrego Taquara, 26/I/2001, Câmara 490 (UB, IBGE); ibidem, tronco árvore, córrego Pitoco, 15/IX/2001, Câmara 601 (UB, IBGE).

Distribuição geográfica: MG, PA, PR, RJ. Primeira ocorrência para o Centro-Oeste.

Comentários: espécie corticícola, M. guatemalense é de ocorrência rara no Brasil estando antes restrita à região sudeste.

20. Schlotheimia rugifolia (Hook.) Schwägr., Spec. Musc. Suppl. 2(1): 150. 1824.

Gametófitos ramificados, medianos, ca. $10 \mathrm{~mm}$ compr.; filídios torcido-espiralados quando secos, ca. $1 \mathrm{~mm}$ compr., ondulados, eretos, oblongo-lanceolados, ápice mucronado, margem inteira, células retangulares a orbiculares, paredes espessas; costa única, percurrente a curto-excurrente, lisa; esporófito não observado.

Descrição e ilustração: Sharp et al. (1994).

Material examinado: BRASIL. Distrito Federal: Reserva Ecológica do IBGE, sobre sobre tronco de árvore, córrego Pitoco, 12/IV/2001, Câmara 542 (UB, IBGE).

Distribuição geográfica: AC, AM, BA, DF, ES, MG, MT, PA, PE, PR, GO, RJ, RO, RS, SC, SP.

Comentários: plantas corticícolas. Macromitrium guatemalense diferencia-se de Schlotheimia rugifolia por seus filídios maiores (até $3 \mathrm{~mm}$ ) e lisos, que em S. rugifolia são rugosos.

21. Schlotheimia jamesonii (Arn.) Brid., Bryol. Univ. 1: 742.1826.

Gametófitos medianos, ca. $10 \mathrm{~mm}$ compr.; filídios torcido-espiralados quando secos, ca. $1 \mathrm{~mm}$ compr., lisos, eretos, oblongo-lanceolados, ápice mucronado, margem inteira, células retangulares a orbiculares, paredes espessas; costa única, percurrente a curto-excurrente, lisa; esporófito não observado.

Descrição e ilustração: Sharp et al. (1994).

Material examinado: BRASIL. Distrito Federal: Reserva Ecológica do IBGE, sobre tronco de árvore, córrego Pitoco, 12/IV/2001, Câmara 542A, Câmara 543 (UB, IBGE). 
RJ, SP.

Distribuição geográfica: AC, DF, MA, MS, PE, PR,

Comentários: diferencia-se de S. rugifolia pelos filídios lisos e os filídios periqueciais obtuso-acuminados.

\section{POLYTRICHACEAE}

22. Pogonatum pensilvanicum (Bartr. ex Hedw.)

P. Beauv., Mém. Soc. Linn. Paris 1: 461. 1823.

Gametófitos ca. $1 \mathrm{~cm}$ compr.; filídios involutos quando secos, ca. $4 \mathrm{~mm}$ compr., lanceolados, ápice serrilhado; lamelas na metade superior do filídio; costa única, percurrente, lisa; esporófito não observado.

Descrição e ilustração: Hyvönen (1989).

Material examinado: BRASIL. Distrito Federal: Reserva Ecológica do IBGE, crescendo em barranco, córrego Taquara, sem data, Mendonça 618 (IBGE).

Distribuição geográfica: ES, GO, MG, PR, RJ, RS, SC, SP. Primeira citação para o DF.

Comentários: caracteriza-se pelas lamelas típicas da família. Outro aspecto interessante são as margens serrilhadas dos filídios que em Pogonatum são mais freqüentes na porção superior dos mesmos.

\section{POTTIACEAE}

23. Hyophila involuta (Hook.) A. Jaeger, Ber. Thätigk. St. Gallischen. Naturwiss. Gesel. 1871-1872: 354 1873.

Gametófitos ca. $2 \mathrm{~mm}$ compr.; filídios fortemente contorcidos e involutos quando secos, ca. de $1 \mathrm{~mm}$ compr., obovado-ligulado, ápice mucronado; costa única, percurrente, lisa; células basais dos filídios pouco diferenciadas, hialinas, quadradas; esporófito não observado.

Descrição e ilustração: Sharp et al. (1994).

Material examinado: BRASIL. Distrito Federal: Reserva Ecológica do IBGE, sobre solo córrego Roncador, 1/IX/2000, Câmara 448 (UB, IBGE).

Distribuição geográfica: AM, BA, ES, DF, GO, PA, PB, PE, PI, PR, MS, MT, RO, RJ, RS, SP.

Comentários: caracterizam-se pelos filídios de forma ovalada-lanceolada, fortemente involutos quando secos. Na RECOR é comum nos ambientes com forte ação antrópica, nas matas de galeria ocorre apenas no Roncador, em trechos com maior ação antrópica como nas proximidades da ponte do Corujão.

24. Tortella humilis (Hedw.) Jenn., Mosses W. Penn. 96. 1913.

Gametófitos medianos, ca. $4 \mathrm{~cm}$ alt.; filídios apressos ou espiralados quando secos, ca. $5 \mathrm{~mm}$ compr., longolanceolados, ápice agudo; costa única, percurrente, lisa; células basais dos filídios levemente diferenciadas, hialinas, formando um "v"; esporófito não observado.

Descrição e ilustração: Puche (2004).

Material analisado: BRASIL. Distrito Federal: Reserva Ecológica do IBGE, sobre tronco de árvore, córrego Pitoco, 12/IV/2001, Câmara 543, Câmara 549 (UB, IBGE); ibidem, sobre madeira no solo da mata, córrego Pitoco, 12/IV/2001, Câmara 551 (UB, IBGE), ibidem, sobre tronco de árvore, córrego Escondido, 15/IX/2001, Câmara 578 (UB, IBGE).

Distribuição geográfica: BA, ES, DF, MG, MS, PR, RJ, RS, SC, SP.

Comentários: este gênero pode ser confundido com Syrrhopodon, do qual se diferencia pelas células basais em forma de "v" e pelo tamanho das mesmas, uma vez que as células hialinas de Syrrhopodon são bem diferenciadas, em Tortella estas não são numerosas e nem formam "v". T. humilis foi encontrada corticícola, embora possa ser saxícola ou terrestre.

\section{RHACHITHECIACEAE}

25.Tisserantiella minutissima (Mitt.) R.H. Zander., Bull. Buffalo Soc. 32: 277. 1993.

Gametófitos ca. de $1 \mathrm{~mm}$ compr.; filídios espiralados quando secos, ca. $1 \mathrm{~mm}$ compr., liguladas; costa única, subpercurrente, terminando poucas células abaixo do ápice, lisa; células basais dos filídios levemente diferenciadas, hialinas; esporófito não observado.

Descrição e ilustração: Câmara \& Vital (2006).

Material examinado: BRASIL. Distrito Federal: Reserva Ecológica do IBGE, sobre tronco caído no solo da mata, córrego Monjolo, 1/IX/2000, Câmara 452 (UB, IBGE); ibidem, sobre tronco de árvore, córrego Pitoco, 12/IV/2001, Câmara 552 (UB, IBGE).

Distribuição geográfica: GO e DF.

Comentários: trata-se da terceira ocorrência para o Brasil. A primeira coleta ocorreu há 120 anos por Gardner, em Serra de Santa Brida (GO) e a coleta seguinte por Schäffer-Verwimp em 1986, em Alto Paraíso de Goiás, GO. Existem duas ocorrências na RECOR, nos córregos Monjolo e Pitoco. Também é citada para a Bolívia (Schaffer-Verwimp 1992). A baixa quantidade de coletas desta espécie parece refletir a falta de coletas ou a identificação errônea ou provavelmente ambos. Para maiores dados sobre essa planta ver Câmara \& Vital (2006).

\section{SPHAGNACEAE}

26. Sphagnum perichaetiale Hampe, Syn. Musc. Frond. 1: 93.1848.

Gametófitos branco-esverdeados, ramificados; leucocistos com espessamentos espiralados, porosos, 
1-3 poros não perfurados por célula; filídios ligulados, ápice arredondado e hialino; ramificações em fascículos de 4-5; filídios dos ramos ovalados ou cuculados; clorocistos lenticulares; esporófito não observado.

Descrição e ilustração: Sharp et al. (1994).

Material examinado: BRASIL. Distrito Federal: Reserva Ecológica do IBGE, sobre solo, córrego Escondido, 15/IX/2001, Câmara 577 (UB, IBGE), ibidem sobre solo, córrego Roncador, 14/XI/1985, Vital s.n. (UB).

Distribuição geográfica: AM, DF, ES, MG, MS, PA, RJ, RO, SC, SP.

Comentários: é reconhecida por sua coloração esbranquiçada, disposição fasciculada dos ramos e forma ligulada dos filídios. Terrestre, de barrancos e áreas alagadas. No córrego Escondido, está restrita às nascentes, ocorre comumente associada a Campylopus controversus.

\section{Agradecimentos}

O autor externa seus agradecimentos a: Prof. Dr. Pedro Américo Cabral Senna (in memoriam), Dra. Denise Pinheiro da Costa (JBRJ), Dra. Olga Yano e Dra. Sandra Visnadi (IBt), Dra. Ana Luiza Ilkiu-Borges (MG), Dr. Tarciso Filgueiras (IBGE), Profa. Dra. Raquel Novellino (UnB), Profa. Dra. Maria da Graças Machado (UnB), Prof. Dr. Carolyn Proenca e Prof. Dr. Fabian Borghetti (UnB) e em especial ao Pesquisador Daniel Moreira Vital (IBt); ao Departamentoto de Botânica da Universidade de Brasília e à administração da Reserva Ecológica do IBGE, em particular a Dra. Iracema Gonzales e Maria Aparecida da Silva, e aos curadores dos herbários visitados.

\section{Referências bibliográficas}

Allen, B.H. 1992. A Revision of Ochrobryum (Leucobryaceae). Contributions University of Michigan Herbarium 18: 113-130.

Anderson, L.E. 1954. Hoyer's solution as a rapid permanent mounting medium for bryologists. The Bryologist 57: 242-244.

Buck, W.R. \& Goffinet, B. 2000. Morphology and classification of mosses. Pp. 72-124. In: Shaw \& Goffinet (eds.). Bryophyte Biology. Cambridge, Cambridge University Press.

Câmara, P.E.A.S. \& Costa, D.P. 2006. Hepáticas e Antóceros das matas de Galeria da Reserva Ecológica do IBGE, RECOR, Distrito Federal, Brasil. Hoehnea 33: 79-87.

Câmara, P.E.A.S. \& Vital, D.M. 2006. Tisserantiella minutissima (Mitt.) R.H. Zander, a new and significant record from Distrito Federal, Brazil. Hoehnea 33: 257-259.

Câmara, P.E.A.S.; Teixeira; R.; Lima, J. \& Lima, J. 2003. Musgos urbanos do Recanto das Emas, Distrito Federal, Brasil. Acta Botanica Brasilica 17: 507-513.

Câmara, P.E.A.S.; Oliveira, J.R.P.M. \& Santiago, M.M.M. 2005. A Checklist of the bryophytes of Distrito Federal (Brasília, Brazil). Tropical Bryology 26: 133-140.
Crum, H.A. 1976. Mosses of the Great Lakes Forest. Michigan, University of Michigan.

Felfili, J.M.; Filgueiras, T.S.; Haridasan; M.; Silva Júnior, M.C.; Mendonça, R.C. \& Resende, A.V. 1994. Projeto Biogeografia do Bioma Cerrado: vegetação, solos. Cadernos de Geociências 12: $75-166$.

Filgueiras, T.S. \& Pereira, B.A.S. 1993. Flora do Distrito Federal In: M.N Pinto (org.). Cerrado: caracterização, ocupação e perspectivas. 2 ed. Brasília, Ed. Universidade de Brasília.

Frahm, J.P. 1991. Dicranaceae: Campylopodioideae, Paraleucobryoideae. Flora Neotropica, Monograph 54: $1-238$.

Genevro, J.A.; Athayde Filho, F.P. \& Peralta, D.F. 2006. Briófitas das matas de galeria no Parque Municipal Mário Viana, Nova Xavantina, Mato Grosso, Brasil. Boletim do Instituto de Botânica 18: 149-157.

Gentry, A.H. 1997. Regional Overview: South America. In: S.D. Davis. (org.). Centres of Plant Diversity. The Americas. v.3. London, WWF/IUCN.

Gradstein, S.R. \& Pócs, T. 1989. Bryophytes. In: H. Leith \& M.J.A. Werger (eds.). Tropical rain forests ecosystems. Amsterdan, Elsevier Science.

Hyvönen, J. 1989. A Synopsis of genus Pogonatum (Polytrichaceae, Musci). Acta Botanica Fennica 138: 1-87.

La Farge-England, C. 1996. Growth form, branching pattern, and perichaetial position in mosses: cladocarpy and pleurocarpy redifined. The Bryologist 99: 170-186.

Lisboa, R.C.L. 1993. Musgos Acrocárpicos do estado de Rondônia. Belém, Museu Paraense Emilio Goeldi. Coleção Adolpho Ducke.

Oliveira, J.R.P.M.; Alvarenga, L.D.P. \& Pôrto, K.C. 2006. Briófitas da Estação Ecológica de Águas Emendadas, Distrito Federal, material coletado por Daniel Moreira Vital. Boletim do Instituto de Botânica 18: 181-195.

Pereira, B.A.S. \& Mamede, L. 1993. Bacia do Taquara (Centro-Sul do Distrito Federal, Brasil): ocupação e uso. http:// www.recor.org.br. (Acesso em: 5/09/2000).

Puche, F. 2004. Pottiaceae: Tortella. Flora Briofítica Ibérica: 5- 15 .

Reese, W.D. 1993. Calymperaceae. Flora Neotropica, Monograph 58: $1-102$.

Rezende, A.V. 1998. Importância das matas de galeria: manutenção e recuperação. In: J.F. Ribeiro. Cerrado, matas de galeria. Brasília, Embrapa-CPAC.

Schafer-Verwimp, A. 1992. New or interesting records of Brazilian Bryophytes, III. The Journal of the Hattori Botanical Laboratory 71: 55-68.

SEMATEC, 1992. Mapa Ambiental do Distrito Federal. Brasília, Secretaria do Meio Ambiente, Ciência e Tecnologia do Governo do Distrito Federal.

Sharp, A.J.; Crum, H.A. \& Eckel, P. 1994. The moss flora of Mexico. Memoirs of The New York Botanical Garden 69: $1-1113$.

Silva Júnior, M.C.; Felfili, J.M.; Nogueira, P.E. \& Rezende, A.V. 1998. Análise florística das matas de galeria no Distrito Federal. Pp. 27-30. In: J.F. Ribeiro (org.). Cerrado, matas de galeria. Planaltina, Embrapa Cerrados.

Vitt, D.H. 1984. Classification of the Bryopsida. Pp. 696-759. In: R.M. Schuster (ed.). New Manual of Bryology. v.2. Nicinan, Hattori Botanical Laboratory.

Yano, O. 1984. Briófitas. Pp. 27-30. In: O. Fidalgo \& V.L.R. Bononi (coords.). Técnicas de coleta, preservação e herborização de material botânico. São Paulo, Instituto de Botânica de São Paulo, Série Documentos. 